\title{
Association between Randall's plaque and calcifying nanoparticles
}

\author{
Neva Çiftçioğlu' \\ Kaveh Vejdani ${ }^{2}$ \\ Olivia Lee ${ }^{2}$ \\ Grace Mathew' \\ Katja M Aho ${ }^{3}$ \\ E Olavi Kajander ${ }^{4}$ \\ David S McKay ${ }^{5}$ \\ Jeffrey A Jones ${ }^{5}$ \\ Marshall L Stoller ${ }^{2}$
}

'Nanobac Pharmaceuticals, Johnson Space Center, Houston, TX, USA; ${ }^{2}$ Department of Urology, University of California at San Francisco, San Francisco, CA, USA; ${ }^{3}$ University of Kuopio, Department of Biosciences/ Biochemistry, Kuopio/Finland;

${ }^{4}$ Nanobac Pharmaceuticals, Tampa, FL, USA; ${ }^{5}$ National Aeronautics and Space Administration, Lyndon B. Johnson Space Center, Houston, TX, USA

Correspondence: Marshall L Stoller Professor and Vice Chairman, University of California at San Francisco, 400 Parnassus Avenue, Suite A-6 I0, San Francisco, CA 94143-0738, USA

$\mathrm{Tel}+\mid$ 4I5-476-16II

Fax + I 415-476-8849

Email mstoller@urology.ucsf.edu
Objectives: Randall initially described calcified subepithelial papillary plaques, which he hypothesized as nidi for urinary calculi. The discovery of calcifying nanoparticles (CNP), also referred to as nanobacteria, in calcified soft tissues has raised another hypothesis about their possible involvement in urinary stone formation. This research is the first attempt to investigate the potential association of these two hypotheses.

Methods: We collected renal papilla and blood samples from 17 human patients who had undergone laparoscopic nephrectomy. Immunohistochemical staining (IHS) was applied using monoclonal antibody $(\mathrm{mAb})$ against $\mathrm{CNP}$. Homogenized papillary tissues and serum samples were cultured for CNP. Scanning electron microscopy (SEM) and energy dispersive X-ray spectroscopy (EDS) were performed on papillary samples. Serum samples were tested for CNP antigen and antibody with enzyme-linked immunosorbent assay (ELISA).

Results: Randall's plaques (RP) were visible on gross inspection in 11 out of 17 samples. IHS was positive for CNP antigen in 8 of the visually positive samples, but in only 1 of the remaining samples. SEM revealed spherical apatite-formations in 14 samples confirmed by EDS analysis. In cultures, all serum samples and 13 tissue homogenates grew CNP. In ELISA, 14 samples were positive for CNP-antigen and 11 samples were positive for CNP-antibody.

Conclusion: There was evidence of a link between detection of CNP and presence of RP. Although causality was not demonstrated, these results suggest that further studies with negative control samples should be made to explore the etiology of RP formation, thus leading to a better understanding of the pathogenesis of stone formation.

Keywords: calcifying nanoparticles, nanobacteria, Randall's plaque, urinary stone

\section{Introduction}

Seventy years ago, Randall examined the papillae of cadaveric renal units and demonstrated that interstitial crystal plaques in the papillary tip were common in stone formers (Randall 1937). These crystals were composed not of calcium oxalate (CaOx), the most common solid phase found in patients with nephrolithiasis, but of calcium phosphate $(\mathrm{CaP})$. He believed that the $\mathrm{CaP}$ crystals serve as a nucleation surface for $\mathrm{CaOx}$ (Randall 1940). In vitro, CaP phases efficiently nucleate $\mathrm{CaOx}$ crystallization (Mandel et al 1996), so that one can easily conjecture that common CaOx stones begin on plaques. Recently, Matlaga and colleagues (2007) analyzed RP and confirmed that they are formed of spherical $\mathrm{CaP}$ deposits with a multilaminated internal morphology (Figures 1A, B). According to the Merck Manual (2006), all pathological calcifications contain snowball-like CaP spheres $200 \mathrm{~nm}$ in size. However, the identity of those spherical formations has remained elusive.

Structures similar to the snowballs were discovered over a decade ago in blood and blood products (Kajander et al 1998). These structures, CNP, were detected in numerous pathological calcifications, such as in kidney stones (Ciftcioglu et al 1999; Khular et al 2004), in atherosclerotic plaques (Miller et al 2004; Puskas et al 2005), 
in psammoma bodies of cancer (Hudelist et al 2004), in prostatic stones (Shoskes et al 2005), and in gallbladder (Wen et al 2005). CNP are calcified (Kajander et al 1998), self-propagating (Ciftcioglu et al 2006) entities, morphologically very similar in mineral composition to spherical bodies observed in RP (Figure 1A-D). Due to lack of their genomic evidence, CNP are controversial agents as prions were, and critics have proposed hypotheses explaining them as precipitates of proteins or crystals (Cisar et al 2000). Although CNP cause specific infection (Ciftcioglu et al 2007), and are detected in pathological calcification, general debate over their existence continues. Methods to detect CNP include immuno-detection techniques using anti-CNP mAbs, culture-techniques and electron microscopy (Miller-Hjelle et al 2003). With these methodologies, important features of CNP and their triggering effect on nephrolithiasis have been suggested: A) CNP consist of tiny, "cell-like" spheres (80-200 nm). They precipitate apatite from media forming apatite-protein complexes on their exterior membrane. This protein-associated mineralization (Vali et al 2001) can reach a diameter of one to several micrometers (Kumar et al 2006; Benzerara et al 2006). B) $14 \%$ of healthy adults in Scandinavia have anti-CNP antibodies (Holmberg 2001). In comparison, $75 \%$ of patients with kidney diseases have CNP antigen in blood (Hjelle et al 2000). C) CNP form apatite units/shells in vitro, morphologically and chemically similar to those in the core of kidney stones, (Figure 2) (Ciftcioglu et al 1999). D) CNP are renotropic (Åkerman et al 1997). E) CNP cause renal stones when injected into rats (Garcia Guerpo et al 2000). F) CNP have been detected in kidney stones (Ciftcioglu et al 1999). G) In vitro, destruction of the calcified apatite shell of CNP with EDTA-chelation reveals

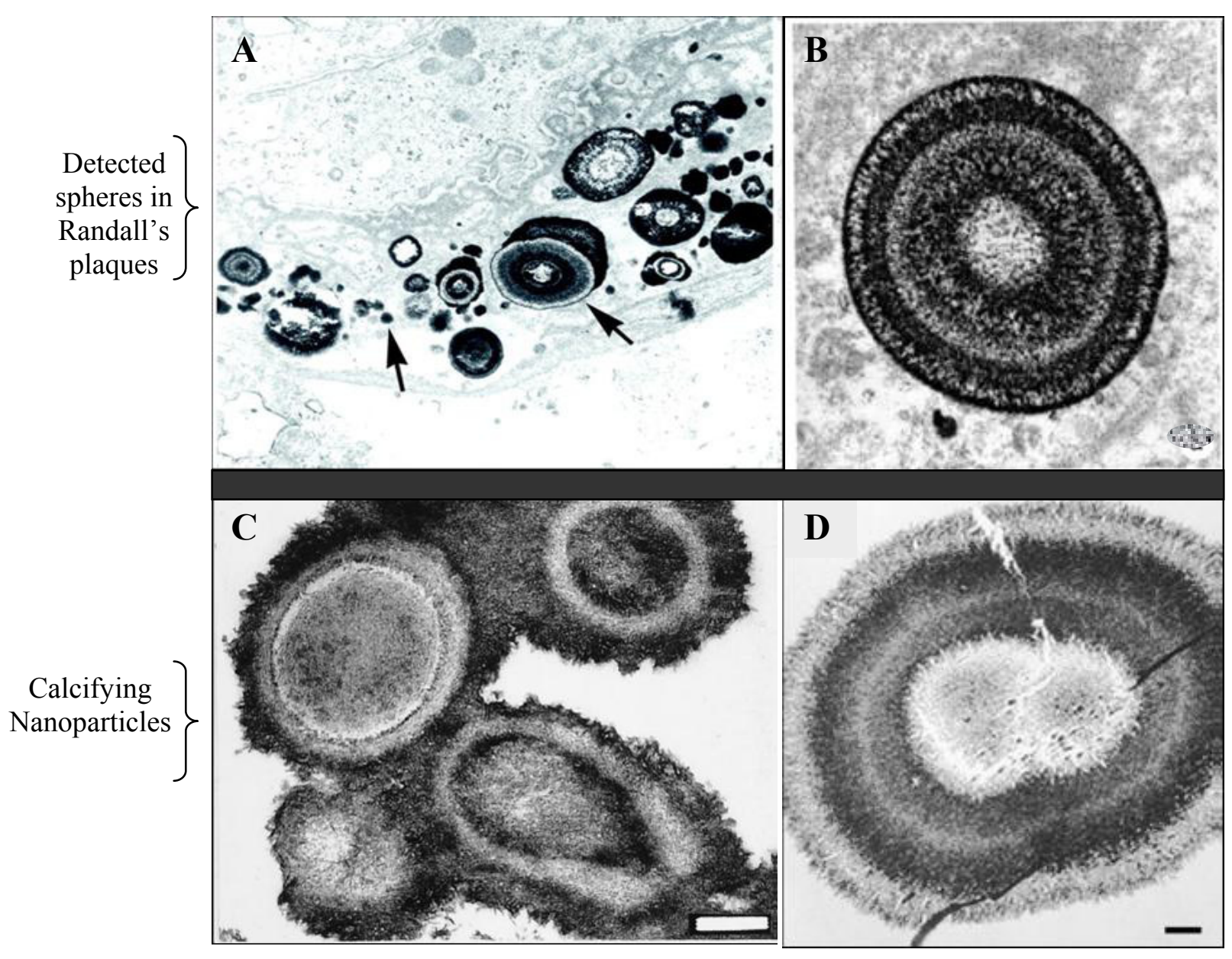

Figure I Morphological similarities of published TEM images of spherical, apatite-containing formations in renal papillae (A and B) and CNP (C and D). Magnifications: A, 20,000X; B, 30,000X; C and D, bars 200 nm. Reprinted from A: Coe FL, Evan A, Worcester E. 2005. Kidney stone disease. J Clin Invest, I I 5:2598-2608, with permission from American Urological Association. B: Matlaga BR, Coe FL, Evan AP, et al 2007. The role of Randall's plaques in the pathogenesis of calcium stones.J Urol, I77:3 I-38, with permission from American Urological Association. C: Kajander EO, Ciftcioglu N. 1998. Nanobacteria: an alternative mechanism for pathogenic intra- and extracellular calcification and stone formation. Proc Natl Acad Sci USA, 95:8274-8279, with permission from National Academy of Sciences USA. D: Kajander EO, Ciftcioglu N,Aho K, et al 2003. Characteristics of nanobacteria and their possible role in stone formation. Urol Res, 31:47-54, with kind permission from Springer Science and Business Media. 

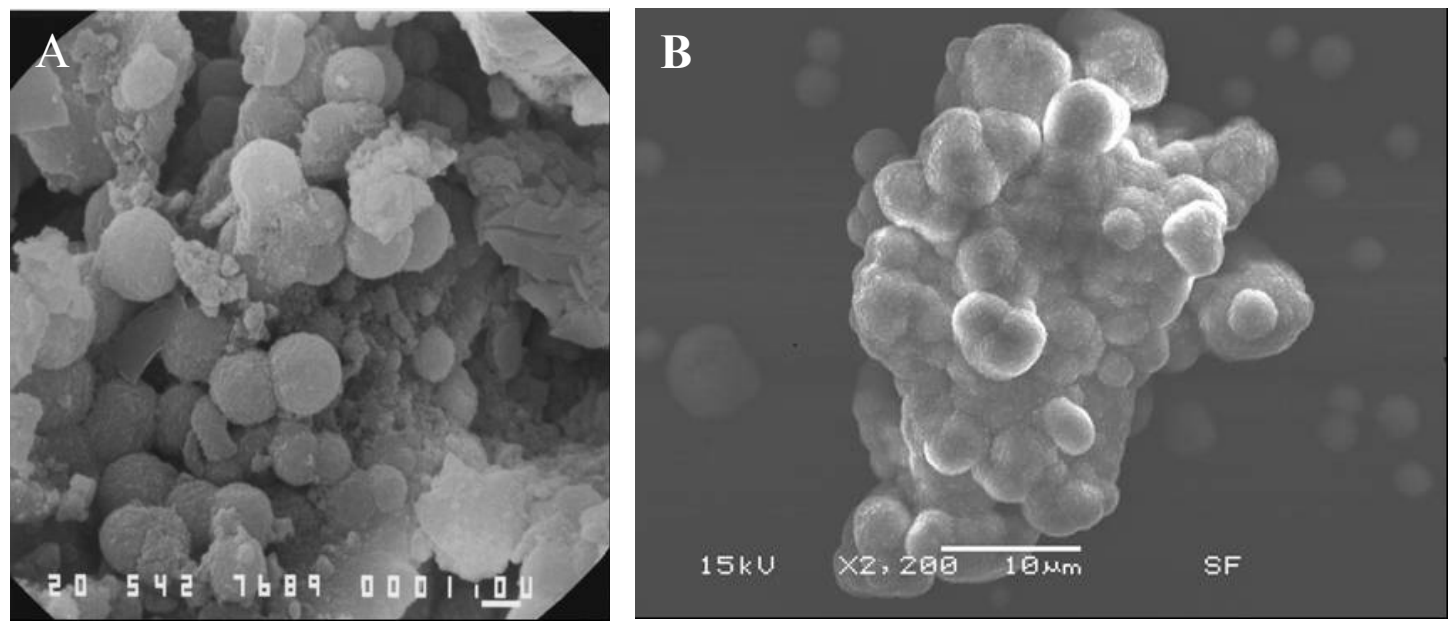

Figure 2 SEM images showing the similarity of apatite spheres in various sizes in the core of an oxalate kidney stone (A) and apatite formations in the CNP culture (B). Bars $=\mathrm{A} ; 1 \mu \mathrm{m}, \mathrm{B} ; 10 \mu \mathrm{m}$.

numerous 50 to $100 \mathrm{~nm}$ diameter membranous cells (Kumar et al 2006) similar to those observed in Randall plaques by other research groups (Matlaga et al 2007). H) TEM study of renal plaques shows $1-5 \mu \mathrm{m}$ apatite spheres, similar to the structure of CNP (Figure 1) (Kajander et al 1998; Matlaga et al 2007).

In this study, our aim was to investigate the association between the presence of $\mathrm{CaP}$ spheres found in $\mathrm{RP}$ and detection of CNP. Such an association would be a basis for a formal hypothesis that can be discussed, and used to drive further studies in larger patient groups.

\section{Materials and methods Subjects}

Renal papillae were dissected from 17 patients who had undergone laparoscopic nephrectomy due to neoplasia (renal cell carcinoma, $n=9$; transitional cell carcinoma, $n=4$; Other malignancies; $n=4$ ). Presence or absence of $R P$ was evaluated on gross inspection of immediately extracted and bivalved kidneys. Intact papillae were harvested well away from the tumor, and were prepared for the analyses with IHS, SEM, EDS and CNP culture. Blood was drawn from fasting patients before and after surgery. The serum was used for CNP culture and ELISA to detect CNP antigen and antibody. Bladder urine samples of patients were collected for routine bacterial culture. The study was approved by the UCSF Committee on Human Research and committee patient confidentiality and informed consent protocols were followed.

\section{Tissue preparation for analysis}

Papillary specimens of 17 patients for IHS and SEM experiments were immersed in $4 \%$ paraformaldehyde and refrigerated overnight. IHS samples were paraffin embedded and prepared for IHS as described earlier (Scheffer et al 2002). SEM samples were dehydrated and gold-coated as described previously (Matlaga et al 2007). The tissue samples for CNP cultures were placed into $2 \mathrm{ml}$ of sterile phosphate buffered saline (PBS), $\mathrm{pH} 7.4$, homogenized for 30-seconds, four times, with 30-second cooling intervals on ice using conventional glass tissue-grinders. Homogenized tissue was centrifuged at $2500 \mathrm{~g}$ for 15 -minutes. The supernatant was separated and sterile-filtered through $0.22 \mu \mathrm{m}$ pore size, nonprotein binding filters (Millipore) into sterile nonadhesive tubes and stored at $-70{ }^{\circ} \mathrm{C}$ until processed for culture as described below.

\section{IHS analysis of papillary samples}

Paraffin-embedded papillary samples were cut into $5 \mu \mathrm{m}$ sections, deparaffinized and rehydrated (Scheffer et al 2002). Each tissue section was demineralized in $250 \mathrm{mM}$ sodium citrate for 24-hours at $+4^{\circ} \mathrm{C}$, to retrieve apatite crystal-covered epitopes prior to IHS. After washing in water, endogenous peroxidase was blocked with $1 \% \mathrm{H}_{2} \mathrm{O}_{2}$ in methanol for 30-minutes. Slides were rinsed in PBS before staining with a catalyzed-signalamplification IHS (Dako, Carpinteria, CA, USA). Anti-CNP mAb, 8D10 (Nanobac Oy, Kuopio, Finland), was used as primary antibody and counterstained with hematoxylin. Negative control sections went through the same staining process, except that the primary mAb step was omitted.

\section{CNP cultures from serum and tissue samples}

The samples were cultured in Dulbecco's Modified Eagle's Medium (DMEM, Gibco Lab Inc., Grand Island, NY) under 
cell culture conditions $\left(37{ }^{\circ} \mathrm{C}, 5 \%-10 \% \mathrm{CO}_{2}, 90 \%-95 \%\right.$ humidity) for 4 weeks. Patient sera were cultured at $10 \%$ final concentration, and tissue homogenates were cultured both with and without fetal bovine serum (FBS) supplementation which previously tested negative for CNP (Atlanta Biologicals, GA) as described earlier (Miller-Hjelle et al 2003). The homogenized tissue pellets were incubated with $30 \mathrm{mM}$ EDTA for 1-hour at room temperature for decalcification, diluted 1:10 in DMEM, and cultured as described above. To eliminate potential conventional-bacterial contamination, each sample was filtered through $0.22 \mu \mathrm{m}$ pore-sized filters before culturing. Cultures were checked for gross bacterial contamination by microscopy and macroscopic observation of turbidity and medium color change from the third day of incubation. Controls containing only culture media were incubated in parallel with the test cultures to determine whether spontaneous precipitation can occur. Every week, cultures were inspected by phase contrast microscopy (Nikon Eclipse TE 2000-U) for CNP propagation. Positive identification of CNP involved typical slow propagation and optical properties, negative signal with Hoechst 33258 dye, and positive signal with indirect immunofluorescence staining (IIFS) (Ciftcioglu et al 2006). Serum and tissue homogenate cultures for CNP were rated $(+)=$ growth in four weeks, $(++)=$ in three weeks, $(+++)=$ in two weeks, and $(++++)=$ in one week, and $(-)=$ no growth in four weeks of incubation. All culture samples were harvested by $14000 \mathrm{~g}$ centrifugation for 30-min at $4{ }^{\circ} \mathrm{C}$ after 30 -days of incubation. The pellets were analyzed for IIFS using CNP surface-antigen-specific mAb 8D10, followed by Alexa Fluor 488 goat-anti-mouse IgG antibody (Miller-Hjelle et al 2003). In addition, Hoechst stain was used to detect conventional bacterial contamination. As a positive control for Hoechst, E. coli (nonpathogenic strain HB101) was used. Fluorescence photographs were taken using an Olympus BX60F5 microscope coupled to a Nikon digital camera DXM 1200F.

\section{SEM and EDS microanalysis}

Papillary samples $2-4 \mathrm{~mm}$ in block size were analyzed both for morphology and chemical composition using JEOL 6340 Field Emission SEM with attached IXRF EDS analyzer (Kajander et al 1998). Each sample was divided into 4 equal mapping areas and scanned for small, 100-500 nm spherical apatite forms. Cultured CNP and one oxalate kidney stone sample (provided by Louis C. Herring Laboratory, Orlando, FL) were prepared for SEM analysis using the same preparation technique for tissue samples. SEM results were rated as $(-)=$ no CNP observed; otherwise as the number of mapped areas in which CNP were seen $(+$ to ++++$)$.

\section{Biochemical assays}

The commercially available ELISA kits for detecting antiCNP IgG and CNP-antigen; Nano-Sero IgG ELISA, and Nanocapture ELISA (Nanobac Oy, Finland), respectively, were used. All measurements were run in duplicates. The detection antibody in Nanocapture recognizes CaP-binding protein-antigen on CNP in a special CaP complex conformation (ELISA kit inserts). There was not enough serum of subject \#17 for ELISA tests. ELISA results were rated as shown in Table 1.

\section{Statistical analysis}

Descriptive results of the various analytic techniques are displayed in terms of ratings in Table 2. Association between SEM findings and CNP growth ratings in tissue cultures was quantified in terms of contingency table analysis (Fisher Exact Test) with ratings collapsed to either $0[\mathrm{rating}=(-)]$ or 1 rating $=(+)-(++++)]$. A similar analysis was made for possible association between SEM and ELISA-Ag concentration ratings.

\section{Results}

\section{Subjects}

Eleven male and 6 female patients were enrolled in our study, with a mean age of $66 \pm 10$ and $78 \pm 11$ years, respectively. Visually, RP were observed on the papillae of 11 patients, with no sexual preponderance. No correlation was found between the observation of RP and the patients' tumor types (Table 3). Urine cultures for conventional bacteria were negative in 12 patients, showed mild growth of genital flora in 3 patients and were positive for enterococcus species in 2 patients.

\section{IHS}

The results of papillae analyzed using IHS is summarized in Table 2. Nine out of 17 tissue samples stained positive for CNP antigen. Positive staining results, as a brown-colored precipitate at the antigen site, are shown in Figures 3A, B, and F. Negative controls that were stained with the same technique by omitting

Table I ELISA result ratings

\begin{tabular}{llllll}
\hline Units/ml & - & + & ++ & ++ & +++ \\
\hline Nanocapture & $<3.5$ & $3.5-10.9$ & II.0-49.9 & $50.0-149.90$ & $>150$ \\
NanoSero & $<0.1$ & $0.1-0.39$ & $0.4-0.49$ & $0.5-0.69$ & $>0.7$ \\
\hline
\end{tabular}


Table 2 Observation of Randall's plaques on gross inspection, and the detection of CNP by various methods

\begin{tabular}{|c|c|c|c|c|c|c|c|c|}
\hline \multirow[t]{2}{*}{ Sample no } & \multicolumn{5}{|c|}{ Tissue analysis } & \multicolumn{3}{|l|}{ Blood analysis } \\
\hline & $\begin{array}{l}\text { Randall's } \\
\text { plaques }\end{array}$ & IHC & SEM & EDS & $\begin{array}{l}\text { Tissue } \\
\text { homogenate } \\
\text { culture for CNP }\end{array}$ & $\begin{array}{l}\text { Serum culture } \\
\text { for CNP }\end{array}$ & ELISA Ag & ELISA Ab \\
\hline I & - & - & - & - & - & +++ & + & - \\
\hline 2 & + & + & ++ & + & - & +++ & + & + \\
\hline 3 & + & + & +++ & + & ++ & ++ & +++ & - \\
\hline 4 & + & - & +++ & + & + & + & +++ & + \\
\hline 5 & + & + & + & + & ++ & +++ & ++ & - \\
\hline 6 & + & + & +++ & + & ++ & ++++ & - & - \\
\hline 7 & - & - & +++ & + & ++ & +++ & + & - \\
\hline 8 & + & + & +r++ & + & + & ++++ & ++++ & + \\
\hline 9 & - & - & +r+t & + & + & ++++ & ++++ & + \\
\hline 10 & - & + & +r+ & + & ++ & ++ & ++ & + \\
\hline II & - & - & ++ & + & + & + & - & + \\
\hline 12 & + & + & - & - & - & + & ++++ & + \\
\hline 13 & - & - & +++ & + & - & + & ++ & + \\
\hline 14 & + & + & + & + & + & + & ++ & + \\
\hline 15 & + & + & - & - & + & + & ++++ & +++ \\
\hline 16 & + & - & ++ & + & + & + & ++ & + \\
\hline 17 & + & - & + & + & +++ & +++ & ND & ND \\
\hline Positive & II & 9 & 14 & 14 & 13 & 17 & 14 & 11 \\
\hline
\end{tabular}

Abbreviations: CNP, calcifying nanoparticles; IHC, immunohistochemistry; SEM, scanning electron microscopy; EDS, energy dispersive X-ray spectroscopy; ND, not done. Notes: The serum and tissue homogenate cultures for CNP have a rating of ++++: growth in one week, +++: growth in two weeks, ++: growth in three weeks, +: growth in four weeks, - : no growth in four weeks of incubation. SEM is rated as 0 if no CNP is observed, I if CNP are seen in one of the four mapped areas, 2 if CNP are seen two of the four mapped area, 3 if CNP are seen three of the four mapped area, and 4 if CNP are seen in every scanned area at I500X magnification. ELISA results are rated according to the ELISA kit manufacturer's "I unit" definition.

the $\mathrm{mAb}$ did not show any nonspecific signal (Figure 3E). Eight papillary samples were IHS negative. (Figures 3C, D).

\section{CNP cultures of serum samples and tissue homogenates}

All serum samples and 13 of 17 papillary tissue homogenates and pellets contained CNP at different growth rates (Table 2). Three serum samples were already positive within 3-days of culture. All propagation-positive samples stained positive with IIFS using anti-CNP mAb (Figure 4A), but stained negative with the Hoechst (Figure 4B), indicating no bacterial contamination in cultures. The positive control

Table 3 Association between the observation of Randall's plaques and the patients' tumor types

\begin{tabular}{llll}
\hline Diagnosis & RP + & RP - & $\begin{array}{l}\text { p-value (chi-square test } \\
\text { of diagnosis versus RP) }\end{array}$ \\
\hline RCC & 4 & 5 & 0.18 \\
TCC & 3 & 1 & 0.92 \\
Other $^{*}$ & 4 & 0 & 0.28 \\
\hline
\end{tabular}

Abbreviations: RCC, renal cell carcinoma; TCC, transitional cell carcinoma. Notes: "Including oncocytoma and medullary fibroma. for Hoechst dye, E. coli, was stained blue (Figure 4D), but no nonspecific-signal was detected with 8D10 (Figure 4C). None of the samples analyzed with IIFS showed autofluorescence prior to staining. SEM of cultured CNP showed typical morphology of CNP (Figure 5A), as described earlier (Ciftcioglu et al 2006). Control cultures revealed no CNP growth, mineralization, or protein precipitation.

\section{SEM Analysis}

Fourteen of 17 tissue samples contained CNP-like spheres in various sizes (Figures 5B-D and 6B). Tissues with visible macroscopic plaques had more apatite spheres compared to the samples with nonvisible plaques in SEM (Figure 7). The tissue cells with those apatite particles looked more deformed with fibrous formations (Figures 5C, D, and 7F) whereas the negative tissue cells appeared more intact (Figures 6A and $7 \mathrm{G}$ ). The spheres produced an EDS pattern (Figure 6C) identical to the CNP EDS patterns as observed in earlier studies (Kajander et al 1998; Ciftcioglu et al 1999).

In SEM analysis, oxalate kidney stone had spherical units in the core, similar to cultured CNP from renal plaques (Figure 2) with identical EDS patterns. 

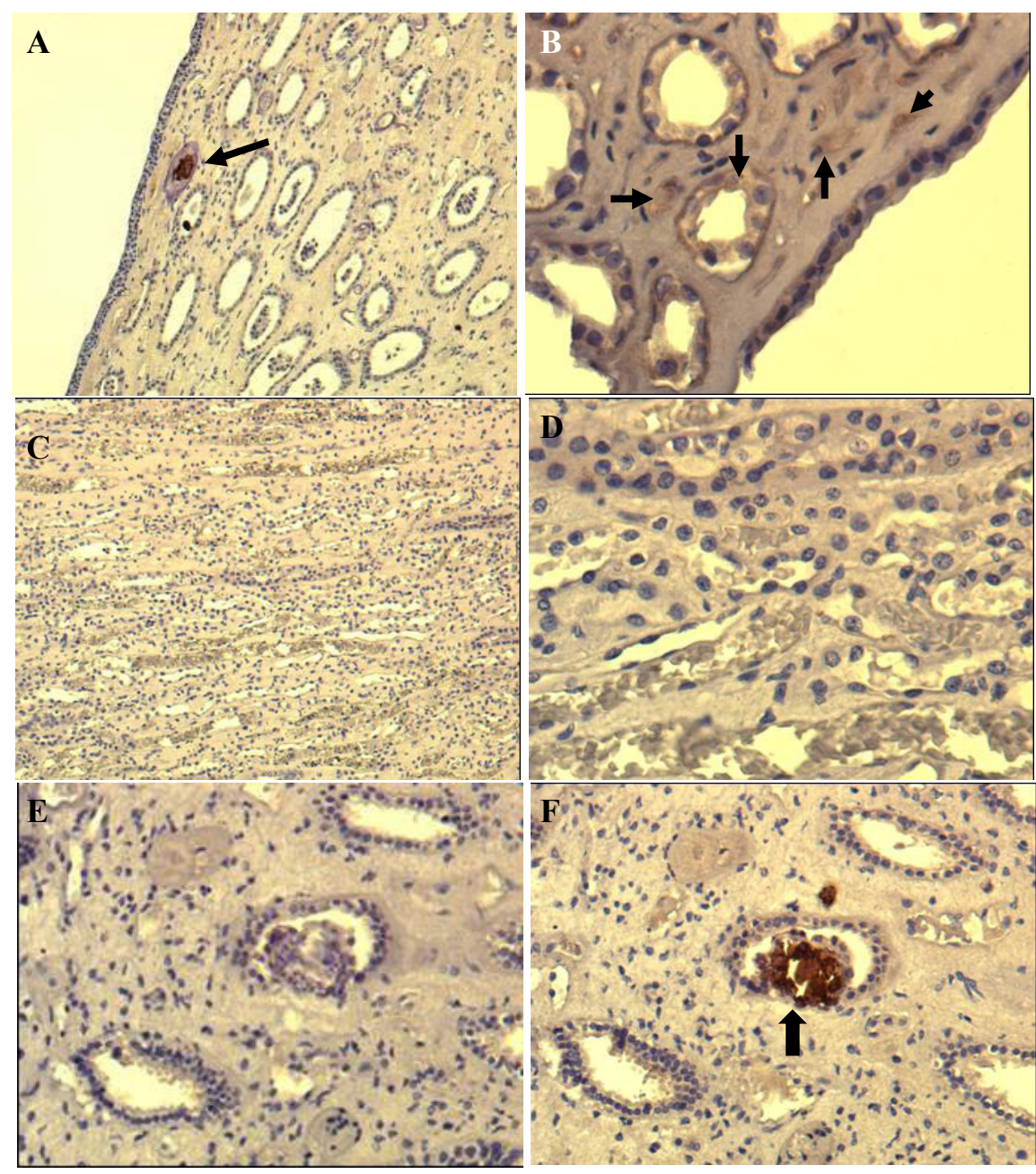

Figure 3 Immunohistochemical (IHS) staining of paraffin-embedded renal tissue by using anti-CNP monoclonal antibody. Brown color shown by black arrows indicates positive signal (existence of CNP antigen) in the tissue. The images shown at A (I00X) and B (200X) are from renal plaque-positive, IHS-positive tissue. C (I00X) and D (400X) are from IHS-negative tissue, $\mathbf{E}$ and $\mathbf{F}(200 X)$ are consecutive sections from a positive tissue. $\mathbf{E}$ is stained by omitting the monoclonal antibody, showing no positive signal whereas $\mathbf{F}$ positively stained in one of the collecting ducts.

\section{ELISA}

Out of 16 tested serum samples, 14 were positive for CNPantigen, and 11 were positive for CNP-antibody. ELISA results are summarized at Table 4. Serum samples collected before and after surgery had no statistical difference showing that the measured biomarkers can be reproducibly measured. The mean antigen values before and after surgery were $184.294 \pm 273.606$ Units $/ \mathrm{ml}$ and $180.103 \pm 275.644$ Units $/ \mathrm{ml}$ respectively. The mean antibody values before and after surgery were $0.169 \pm$ $0.136 \mathrm{Units} / \mathrm{ml}$ and $0.150 \pm 0.148 \mathrm{Units} / \mathrm{ml}$ respectively.

\section{Association between CNP and SEM detection of RP}

Two-by-two contingency tables for SEM (detection of spherical apatite formations on renal papilla) versus tissue culture growth and SEM versus ELISA-Ag concentration ratings are shown in Tables 5 and 6 , respectively. Note that 12 of 14 positive SEM samples showed CNP growth, while 1 of 3 negative samples showed growth (Table 5, $p=0.121$, Fisher's Exact Test). On the other hand the ELISA-Ag results were preponderantly positive regardless of the SEM results (Table 6, $\mathrm{p}=0.650$, Fisher's Exact Test).

\section{Discussion}

Plaques, defined as sites of interstitial crystal deposition at or near the papillary tip, are found in kidneys of $\mathrm{CaOx}-$ stone formers (100\%) and often, but less frequently (43\%), in people who do not form $\mathrm{CaOx}$ stones (Low et al 1997). The nucleus of these plaques are composed of $\mathrm{CaP}$ (Coe et al 2005). Despite extensive studies on RP, the etiology of the initial $\mathrm{CaP}$ accumulation remains elusive. 

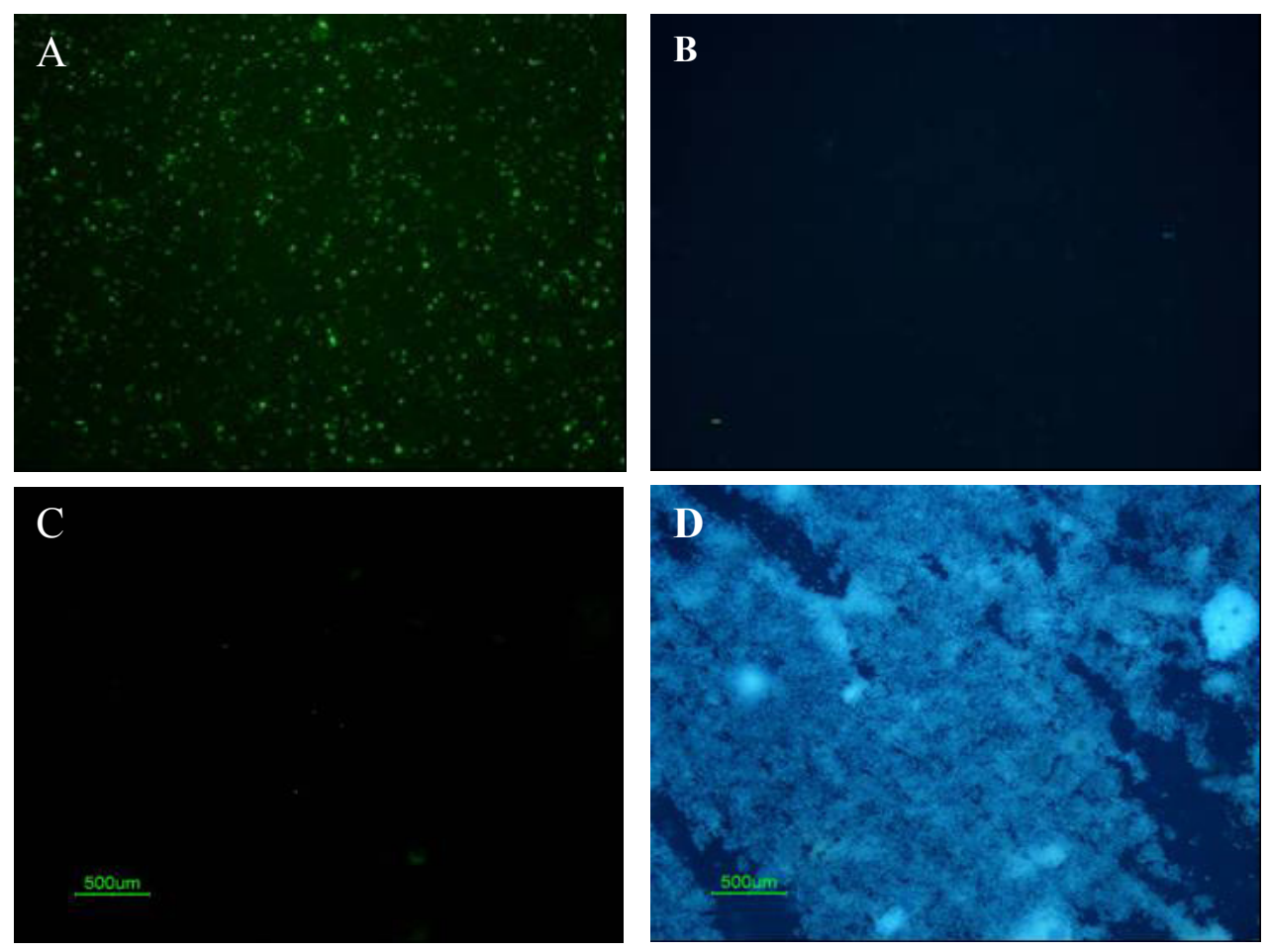

Figure 4 Light microscopic images of double staining results of patient samples cultured under CNP culture conditions. (A) IIFS of cultured patient samples showed positive fluorescence signal using monoclonal antibody 8DI0 when imaged with the green bandpass emission filter, (B) Negative results of Hoechst dye of sample A imaged with the blue bandpass emission filter. (C) IIFS of negative bacterial control (nonpathogenic E. coli strain HBIOI) showed no fluorescence signal using CNP-specific monoclonal antibody when imaged with green bandpass emission filter. (D) Positive results of Hoechst dye of sample C imaged with the blue bandpass emission filter.
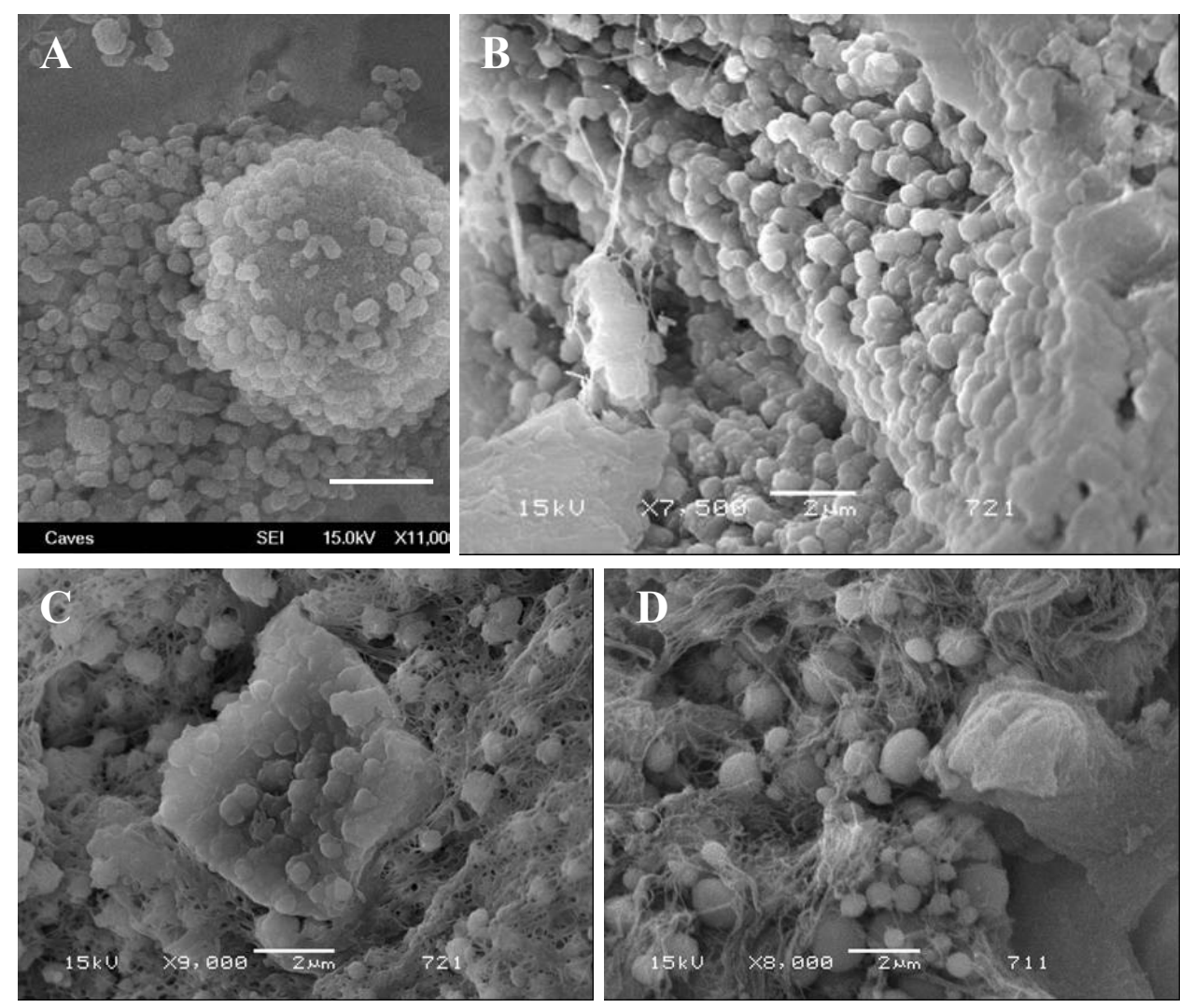

Figure 5 SEM images of (A): cultured CNPs from a serum sample, (B, C, and D): CaP spheres detected on renal papilla (Randall's plaque). Bars; $2 \mu \mathrm{m}$. 

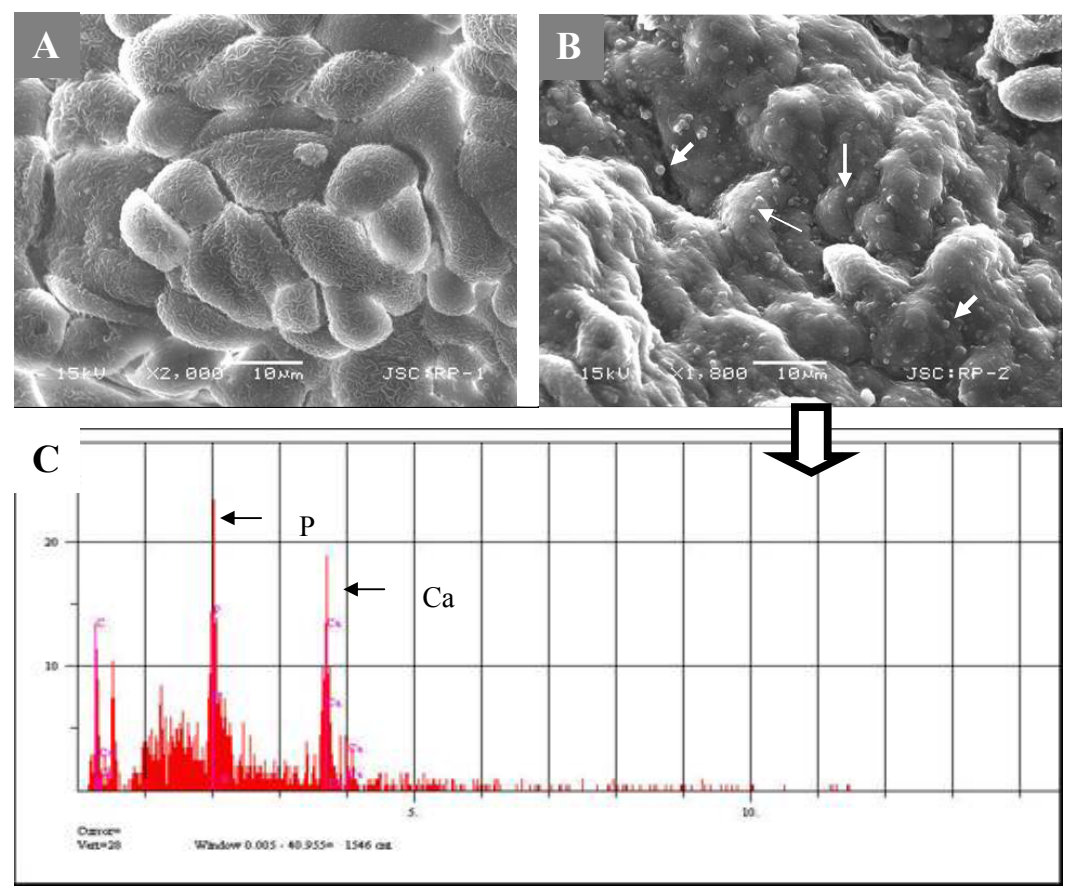

Figure 6 SEM analysis of renal papilla and EDS analysis. A, Renal cells with no plaques. B, renal cells with plaque formations showing bumpy surface. White arrows show the spherical apatite formations on renal cells. C, EDS analysis of the one representative apatite sphere on the cells shown in $\mathbf{B}$.
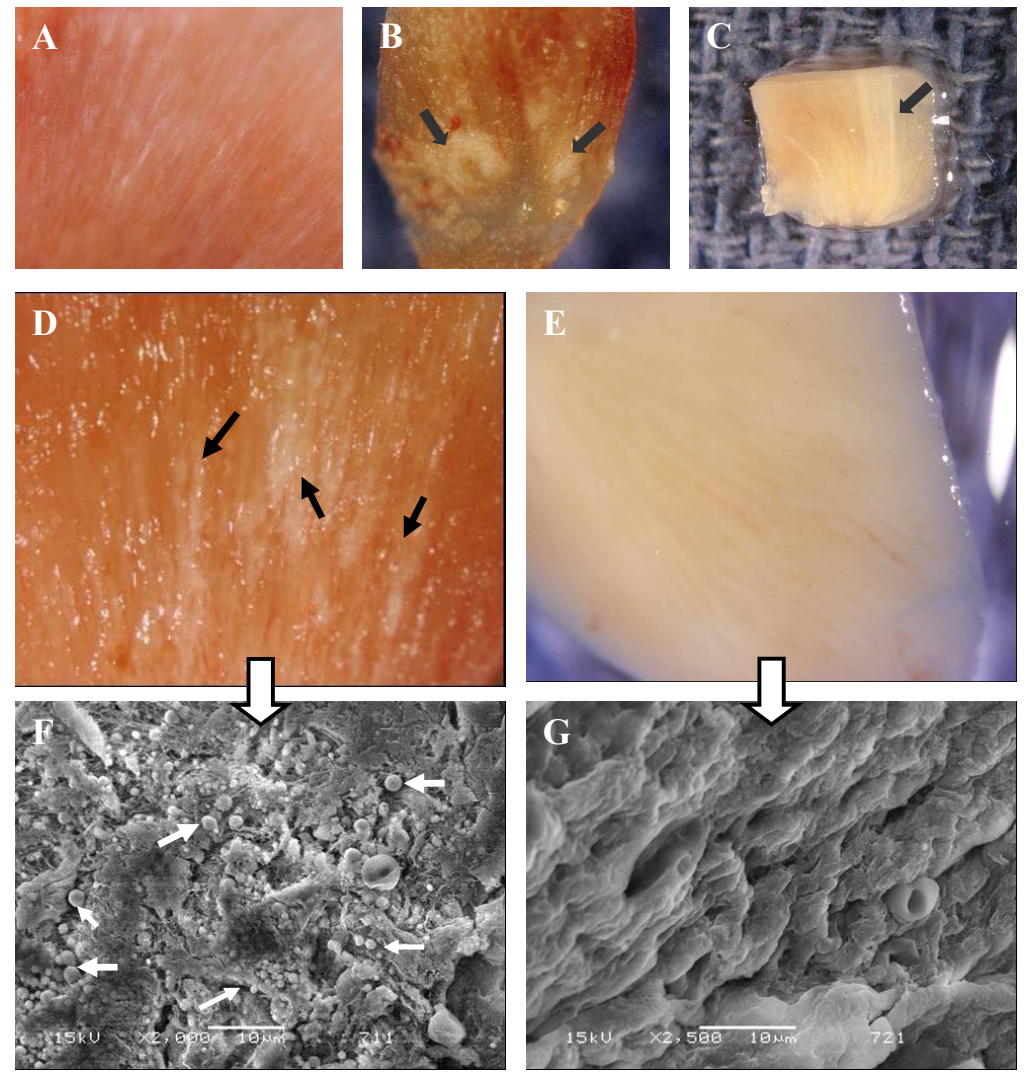

Figure 7 Images from Randall's plaques. (A) Tiny calcifications at the tip of the renal papilla. (B) Relatively large calcified plaques. (C) A cross section through the renal papilla, showing sub-epithelial calcifications running deep into the renal medulla (approximately $3 \mathrm{~mm}$ ). Images of renal papillary tissue with (D) and without (E) visible plaque formations. and their SEM images $(\mathbf{F})$ and $(\mathbf{G})$, respectively. Black arrows show streaks of plaques in the tissue, white small arrows show the apatite spheres on the tissue. Bars in $\mathbf{F}$ and $\mathbf{G}$ are $10 \mu \mathrm{m}$. 
Table 4 Summary of ELISA results

\begin{tabular}{llllll}
\hline Units/ml & - & + & ++ & ++ & +++ \\
\hline Nanocapture & $2 / 16$ & $2 / 16$ & $5 / 16$ & $3 / 16$ & $4 / 16$ \\
NanoSero & $5 / 16$ & $10 / 16$ & $1 / 16$ & $0 / 16$ & $0 / 16$
\end{tabular}

The detection of CNP in human urinary stones (Ciftcioglu et al 1999; Shiekh et al 2006) inspired the hypothesis that CNP might be the initiating agents in the formation of RP and subsequently renal stones. CNP resemble the snowballs $(\sim 0.1-0.5 \mu \mathrm{m})$ from pathological calcifications described by Merck Manual. In addition, they cause rapid in situ precipitation of $\mathrm{CaP}$ from blood and other body fluids under conditions not normally conducive to such precipitation (Kajander et al 1998). CNP are renotropic, as reported from rabbit experiments using injected radiolabelled-CNP and are eliminated from the circulation through urinary excretion (Åkerman et al 1997). It was also shown that translumbar, percutaneous, intrarenal injection of CNP into rats resulted in renal stone formation (Garcia-Guerpo et al 2000). Whether CNP themselves serve as the nucleus for crystal formation by simply lowering the activation barrier or they induce calcification by some other mechanism under much lower supersaturation conditions is yet to be determined.

In this study, we investigated the presence of CNP in the RP of non stone-forming patients. For apparent reasons, kidneys could not be obtained from healthy subjects to serve as negative controls. Similarly, kidneys from renal stone patients are normally not removed, unless complicated by severe hydronephrosis or superimposed pyelonephritis. All subjects in our study had their kidneys removed due to a renal mass.

We observed RP in $65 \%$ of the kidneys, and searched for CNP in the renal papillae through IHS, SEM, and culture techniques. $72 \%$ of plaque-positive tissues were positive for CNP antigen in IHS whereas $83 \%$ of plaque-negative tissues were negative, indicating a statistically significant association $(p=0.043)$. Negative IHS in plaque-positive samples

Table 5 Fisher's exact analysis of SEM/EDS test results versus CNP propagation from the papillary tissue results

\begin{tabular}{llll}
\hline SEM/EDS & \multicolumn{2}{l}{$\begin{array}{l}\text { CNP propagation from } \\
\text { the tissue homogenate }\end{array}$} & Total \\
\cline { 2 - 3 } & $\mathbf{0}$ & $\mathrm{I}$ & \\
\hline $\mathbf{0}$ & 2 & $\mathrm{I}$ & 3 \\
$\mathrm{I}$ & 2 & 12 & 14 \\
Total & 4 & 13 & 17 \\
\hline
\end{tabular}

Notes: Fisher's exact $=0.121$; I-sided Fisher's exact $=0.121$. could happen if the section plane does not pass through the plaque. On the other hand, a plaque-negative sample may stain positive if CNP antigen is present in the tissue but macroscopically undetectable.

SEM of papillae revealed CNP-like spheres in the majority of samples, irrespective of the presence of visible RP (Figure 5). As with IHS, CNP morphology may not be observed in a plaque-positive tissue if the SEM section plane does not include the plaque. Similarly, CNP may be detected in a plaque-negative sample in the early stages of plaque development. This is in agreement with the hypothesis that all large renal stones begin as small calculi and large RP begin as minuscule calcifications. This may explain some of our CNP detection in plaque-negative samples. In EDS analysis, only the CNP-like spheres on papillae produced calcium and phosphate peaks identical to that of CNP in previous reports.

In our earlier TEM analysis of CNP shells, we described their morphology as "tree-age-ring-like" formations of crystal and organic matter (Kajander et al 2003), a description which is almost identical to observations in RP (Figure 1) by others (Coe et al 2005). We also have observed apatite spherical-formations in the core of kidney stones independent of their overall chemical composition (Figure 2), and cultured CNP from those stones (Ciftcioglu et al 1999).

To see if these apatite spheres are actually capable of propagating, we cultured the papillary tissue extracts obtained from our patients. Thirteen of 17 samples grew CNP within 4 weeks (Table 2), which were identified by IIFS of harvested culture pellets with the CNP-specific mAb. We cultured patient sera obtained before and after surgery, all of which turned positive within 4-weeks (Table 3). The differences observed in the propagation rate may reflect existence of CNP in different concentrations. ELISA tests measuring CNP antigen (14/16) and antibody (11/16) in sera also strongly correlate with culture results.

To a great extent, our studies accord with and confirm much of Randall's pioneering work. The plaque is interstitial and composed of apatite. What we add here is that many of the apatite formations can propagate in cultures and are stainable with CNP-specific mAb. Therefore one conclusion could be that RP contain CNP. Where do these CNP come from? Stoller and colleagues (1996) suggested a vascular origin for RP. We have detected CNP in blood (Kajander et al 1998). CNP may form foci or agglomerate in kidneys when excreted in the urine and ultimately may develop into RP (Kajander et al 2003). CaP spheres $200 \mathrm{~nm}$ in size have been observed in many pathological 
Table 6 Fisher's exact analysis of SEM/EDS test results versus ELISA-Ag test results

\begin{tabular}{llll}
\hline SEM/EDS & \multicolumn{2}{c}{ ELISA-Ag results } & Total \\
\cline { 2 - 4 } & $\mathbf{0}$ & $\mathbf{I}$ & \\
\hline $\mathbf{0}$ & 0 & 3 & 3 \\
I & 2 & $\mathrm{II}$ & 13 \\
Total & 2 & 14 & 16 \\
\hline
\end{tabular}

Notes: Fisher's exact $=1.000 ;$ I-sided Fisher's exact $=0.650$.

calcifications (Carson 1998) including atherosclerotic and RP. Interestingly, CNP have been detected in similar calcifications (Miller et al 2004). CNP could be the elusive CaP snowballs found in pathological calcifications.

\section{Conclusion}

There is a correlation between RP and the presence of CNP. If supported by further work, the establishment of CNP as the etiology of RP will direct a fundamentally novel treatment approach for urinary stone disease. If so, inhibiting the propagation of CNP (Ciftcioglu et al 2002) would make urinary stone prevention a conceivable possibility.

\section{Acknowledgments}

This research was funded by ARES/Astrobiology at NASA Johnson Space Center (JSC), and Nanobac Pharmaceuticals Inc. We thank Dr Alan H Feiveson (NASA, JSC) for statistical analysis, Dr Adam Hittelman at University of California at San Francisco (UCSF) for coordinating patients' serum and tissue samples, Dr Craig Schwandt (NASA, JSC) for his support in electron microscopy, and Dr Jean Olson (UCSF) for her assistance in evaluating immunohistochemistry interpretaton. Special thanks to Mission Pharmacal for providing discussion points on stone formation. Our gratitude to Dr Dan Garrison (NASA JSC) for his efficient management of BSL-2 laboratories and Charles Galindo (NASA, JSC) for his assistance. Patrice Colbert's (NASA, JSC) proficiency in editing the text is greatly appreciated. The authors report no conflict of interest in this manuscript.

\section{References}

Åkerman KK, Kuikka JT, Çiftçioglu N et al. 1997. Radiolabeling and in vivo distribution of nanobacteria in rabbit. In: Hoover RB, ed. Instruments, Methods, and Missions for Astrobiology, The International Society for Optical Engineering. Proceedings of SPIE, 3111:436-42.

Benzerara K, Miller VM, Barell G et al. 2006. Search for microbial signatures within human and microbial calcifications using soft $\mathrm{x}$-ray spectromicroscopy. J Investig Med, 54:367-79.

Carson DA. 1998. An infectious origin of extraskeletal calcification. Proc Natl Acad Sci USA, 95:7846-7.
Ciftcioglu N, Miller-Hjelle MA, Hjelle JT et al. 2002. Inhibition of nanobacteria by antimicrobial drugs as measured by modified microdilution method. Antimicrob Agents Chemother, 46:2077-86.

Ciftcioglu N, McKay DS, Mathew G et al. 2006. Nanobacteria: fact or fiction? Characteristics, detection, and medical importance of novel self-replicating, calcifying nanoparticles. J Investig Med, 54:385-94.

Ciftcioglu N, Aho KM, McKay DS et al. 2007. Are apatite nanoparticles safe? Lancet, 9579:2078

Ciftcioglu N, Björklund M, Willman K et al. 1999. Nanobacteria: an infectious cause for kidney stone formation. Kid Int, 56:1893-98.

Cisar JO, Xu DQ, Thompson J et al. 2000. An alternative interpretation of nanobacteria-induced biomineralization. Proc Natl Acad Sci USA, 21:11511-5.

Coe FL, Evan A, Worcester E. 2005. Kidney stone disease. J Clin Invest, 115:2598-608.

García Cuerpo E, Kajander EO, Çiftçioğlu N et al. 2000. Nanobacteria; Un modelo de neo-litogenesis experimental. Arch Esp Urol, 53:291-303.

Hjelle JT, Miller-Hjelle MA, Poxton IR et al. 2000. Endotoxin and nanobacteria in polycystic kidney disease. Kid Int, 57:2360-74.

Holmberg M. 2001. Prevalence of human anti-nanobacteria antibodies suggest possible zoonosis [online]. 1st International Minisymposium on Nanobacteria, Kuopio, Finland. Accessed on 10 Jan, 2008. URL:http://www.nanobac.fi/nbminisymp080301/page10.html

Hudelist G, Singer CF, Kubista E et al. 2004. Presence of nanobacteria in psammoma bodies of ovarian cancer: evidence for pathogenetic role in intratumoral biomineralization. Histopathology, 45:633-37.

Kajander EO, Çiftçioğlu N. 1998. Nanobacteria: An alternative mechanism for pathogenic intra- and extracellular calcification and stone formation. Proc Natl Acad Sci USA, 95:8274-79.

Kajander EO, Çiftçioğlu N, Aho K et al. 2003. Characteristics of nanobacteria and their possible role in stone formation. Urol Res, 31:47-54.

Khullar M, Sharma SK, Singh SK et al. 2004. Morphological and immunological characteristics of nanobacteria from human renal stones of a north Indian population. Urol Res, 32:190-95.

Kumar V, Farell G, Yu S et al. 2006. Cell biology of pathologic renal calcification: contribution of crystal transcytosis, cell-mediated calcification, and nanoparticles. J Investig Med, 54:412-24.

Low RK, Stoller ML. 1997. Endoscopic mapping of renal papillae for Randall's plaques in patients with urinary stone disease. J Urol, 158:2062-64.

Mandel GS, Mandel NS. 1996. Crystal-crystal interactions, In: Coe FL, Favus MJ, Pak CYC, et al. eds. Kidney stones: medical and surgical management. Philadelphia: Lippincott-Raven Publishers pp. 115-28.

Matlaga BR, Coe FL, Evan AP et al. 2007. The role of Randall's palques in the pathogenesis of calcium stones. $J$ Urol, 177:31-38.

Miller-Hjelle MA, Hjelle JT, Çiftçioğlu N et al. 2003. Nanobacteria: Methods for growth and identification of this recently discovered calciferous agent. In: Olson WP, ed. Rapid Analytical Microbiology. The Chemistry and Physics of Microbial Identification. Bethesda, MD: Davis Horwood International Publishing, Ltd pp. 297-312.

Miller VM, Rodgers G, Charlesworth JA et al. 2004. Evidence of nanobacterial-like structures in calcified human arteries and cardiac valves. Am J Physiol Heart Circ Physiol, 287:1115-124.

Puskás LG, Tiszlavicz L, Rázga Z et al. 2005. Detection of nanobacterialike particles in human atherosclerotic plaques. Acta Biol Hung, 56:233-45.

Randall A. 1937. The origin and growth of renal calculi. Ann Surg, 105:1009-27.

Randall A. 1940. Papillary pathology as precursor of primary renal calculus. J Urol, 44:580-89.

Scheffer GL, Hu X, Pijnenborg AC et al. 2002. MRP6 (ABCC6) detection in normal human tissues and tumors. Lab Invest, 82:515-18.

Shiekh FA, Khullar M, Singh SK. 2006. Lithogenesis: induction of renal calcifications by nanobacteria. Urol Res, 34:53-7.

Shoskes DA, Thomas KD, Gomez E. 2005. Anti-nanobacterial therapy for men with chronic prostatitis/chronic pelvic pain syndrome and prostatic stones: preliminary experience. J Urol, 173:474-77. 
Stoller ML, Low RK, Shami GS et al. 1996. High resolution radiography of cadaveric kidneys: unraveling the mystery of Randall's plaque formation. J Urol, 156:1263-6.

The Merck Manual of Diagnosis and Therapy, 18th edition, section 4. 2006. In: Beers MH, Porter RS, Jones TV, et al. eds. Musculoskeletal and Connective Tissue Disorders. Whitehouse Station, NJ: Merck Research Laboratories. Division of Merck and Co. Incpp 304.

Vali H, McKee MD, Çiftçioğlu N et al. 2001. Nanoforms: A new type of protein-associated Mineralization. Geoch Cosmoch Acta, 65:63-74.

Wen Y, Li YG, Yang ZL et al. 2005. Detection of nanobacteria in serum, bile and gallbladder mucosa of patients with cholecystolithiasis. Chin Med J, 118:421-24. 
